\title{
ANTONIA CLEMENTINA, PROPIETARIA DE TIERRAS EN LA COLONIA IULIA URBS TRIUMPHALIS TARRACO ANTONIA CLEMENTINA, LANDOWNER IN THE COLONIA IULIA URBS TRIUMPHALIS TARRACO
}

\author{
Ma CARMEN DELIA GREGORIO NAVARRO \\ Universidad de Zaragoza
}

Recepción: 15-06-2009; Aceptación: 09-10-2009

\section{INTRODUCCIÓN}

El Siglo de Oro español no sólo lo fue de la literatura, sino también de la investigación arqueológica. Acogió la publicación de buen número de obras en las que se reflejaron los descubrimientos en materia de arqueología, constituyendo auténticos catálogos de museos con información pormenorizada de los hallazgos, y en el caso de los epígrafes, su descripción y traducción. Es en este ambiente de producción intelectual fecunda cuando Ambrosio de Morales, cronista del rey Felipe II (sacerdote, historiador y arqueólogo) publica en 1575 su compendio de Las antigüedades de las ciudades de España donde ya aparece mencionada la inscripción funeraria de la romana Antonia Clementina, cuya ubicación en el claustro de la Catedral de Tarragona (Fig. 1) se conoce desde el siglo XV (De Morales, 1575, 23; RIT 368). Ya entonces Ambrosio de Morales la clasificó por el interés que despertaban sus cláusulas testamentarias, grabadas en la piedra, aunque de práctica común en la época como veremos más adelante, pues según dice el autor: «Tambien se hallan en España algunas piedras antiguas escritas, que son manifiestamente testamentos mezclados con sepulturas: y assi parece que no tienen que ver con las quatro maneras de las otras ${ }^{1}$,

1. Las otras quatro maneras a las que se refiere son: «sepulturas, o medidas de caminos, o aras y altares, o son dedicaciones de alguna cosa que se hazia en reuerencia de algun templo, o de algun Emperador, o de otra persona publica o particular, cuya memoria querian que durasse para adelante. Estas quatro maneras de piedras antiguas son muy ordinarias, assi en España, como en otras provincias: y dellas solamente hemos de tratar aquí. Mas porque ay algunas otras maneras de piedras diuersas destas, diremos dellas despues a su tiempo: que agora no quise mas de aduertirlo, porque nadie no tenga por defectuosa esta división, por faltarle algo de lo que deuiera incluir y abraçar. Para los exemplos pondre algunas piedras de nuevo, mas no se pondran las que ya quedan puestas en la Coronica: pues facilmente se pueden hallar, y fuera mucha pesadumbre bo-

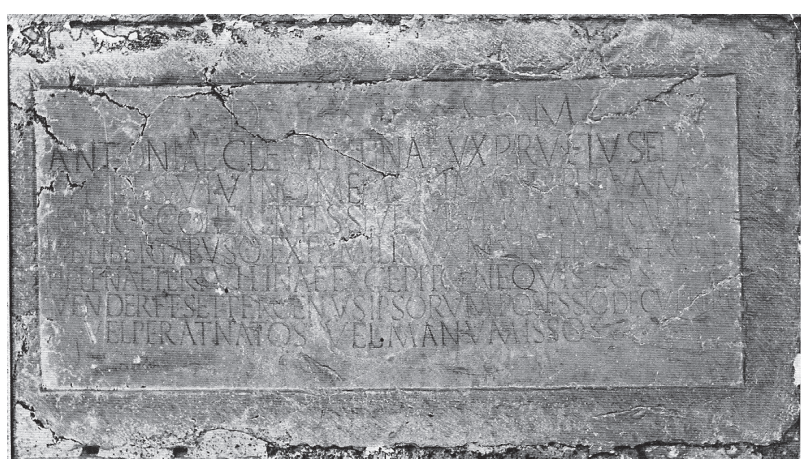

Figura 1: Inscripción de Antonia Clementina en el claustro de la Catedral de Tarragona. Alföldy, G., 1975: Die römischen Inschriften von Tarraco, Berlín, lámina XCV 2.

que arriba hemos señalado. Tal es esta gran piedra que está en Tarragona enel claustro de la Yglesia de San Miguel $^{2} \gg$.

Unos años antes de la aparición de la obra de Ambrosio de Morales, en 1572, se había publicado en Lérida el Libro de las Grandezas y cosas memorables de la ciudad de Tarragona, del tarraconense Lluis Pons d'Icart, donde también se mencionaban algunas inscripciones de la ciudad. Y posteriormente, en 1713, el ingeniero también tarraconense Ioseph Boy, sacaría a la luz su Recopilación sussinta de las antiguedades romanas q se allan del tiempo de los Emperadores romanos en la ciudad de Tarragona y sus cercanias. Copia-

luerlas a repetir», cfr. A. de Morales (1575, folios 11-23).

2. En la época que Ambrosio de Morales escribe, la Catedral de Tarragona había sufrido ya varias reformas que aumentaron paulatinamente la primitiva planta, pasando a denominarse a partir de entonces como de Santa María de Tarragona (de los siglos XI al XIII fue de Santa Tecla «la Vieja»), cfr. P. Batlle Huguet $(1979,4)$. La capilla de San Miguel, adosada al Baptisterio, fue construida a expensas del canónigo Guillermo Botsoms hacia 1365, cfr. P. Batlle Huguet $(1979,40)$. 
das y escritas de las mesmas antigüedades por Ioseph Boy Ingeniero en dicha ciudad. En su obra también aparecía la inscripción del claustro (Boy, 1713, 55).

Ya en la segunda mitad del siglo XIX, el clasicista Emil Hübner incluyó la inscripción de Antonia Clementina en el volumen del Corpus Inscriptionum Latinarum dedicado a Hispania, acompañándola de una extensa bibliografía (CIL II, 4332). A fines del mismo siglo, el erudito tarraconense Emilio Morera y Llauradó nos informa, recogiendo la tradición anterior, que la inscripción fue colocada en la Catedral como cualquier otro sillar, en uno de los muros interiores del Claustro, entre la puerta de entrada al mismo «y la puerta de comunicación con la Sacristía» (Elías Riera, 1946, 3-4).

La catedral de Santa María de Tarragona, construida en la parte más alta del núcleo urbano antiguo, estuvo dedicada en origen a Santa Tecla, patrona de la ciudad junto a San Magí. Este dato es conocido gracias a la donación que hace el conde barcelonés Ramón Berenguer III al obispo Olegario de Barcelona en 1118 (el mismo año de la conquista de Saraqusta, la Zaragoza árabe, por Alfonso I el Batallador), en el que le cede, además de la ciudad y el Campo de Tarragona, la sede de la Iglesia tarraconense, dedicada a Santa Tecla. Es entre mediados del siglo XII y la primera mitad del siglo XIV cuando se desarrolla la restauración arquitectónica que convertiría a la primitiva iglesia en el gran complejo religioso que es hoy día, a lo que contribuyeron numerosas donaciones. Respecto al claustro, cuya construcción se encuentra documentada en el testamento, de 1214, del prelado Ramón de Rocabertí (1198-1215), se data entre los primeros años del siglo XII, y el primer tercio del siglo XIII (Ramos, 1995, 122-124, 126).

Los cimientos de la Catedral se construyeron sobre estructuras de época romana. La superficie en la que hoy día se asienta aquélla, estaba ocupada en el siglo I por dos grandes plazas: la inferior, de representación político-religiosa, y la superior, un recinto del culto imperial. Ésta última, un espacio de 153 por 136 metros, estaba rodeada por un temenos, gran muro de opus quadratum, del que se ha descubierto una gran parte en los Trabajos Arqueológicos del Plan Director de la Catedral, desarrollados entre los años 2000 y 2002, e igualmente un importante sistema de drenaje de la misma época romana. Además, una parte de este muro se utilizó para la construcción de la Catedral (Macías, Menchon, Muñoz y Teixell, 2003-2004, 223-225, 226-228), según nos dice Pedro Batlle: «Los muros de las alas norte y este del claustro, forradas en su interior por piedras de labor románica, son, externamente, extensos lienzos de grandes sillares, con un gran portal y varias ventanas, formando el ángulo de la fachada de una gran construcción romana» (Batlle Huguet, 1979, 3).
Por tanto, el edificio religioso se construyó sobre los restos de un gran complejo romano y reutilizando buen número de sus antiguos materiales (Batlle $\mathrm{Hu}-$ guet, 1979, 51); algunos de los cuales están expuestos en el Museo Diocesano de la ciudad.

Desde principios del siglo XX, el epitafio ha sido objeto de estudio por eruditos en la materia, como Herman Dessau en sus Inscriptiones Latinae Selectae (ILS 8271), y también por historiadores del Derecho, debido esto a «que es considerada como la primera manifestación de los fideicomisos familiares» (Beneyto Pérez, 1931, 84). Pero sería por la misma época, en la década de los años 20 y 30 del siglo XX, cuando los escritos sobre la antigua Tarraco adquirieron un mayor rigor científico con la publicación de las memorias de excavación arqueológica realizadas y dirigidas por el canónigo Juan Serra Vilaró ${ }^{3}$, y cuya labor principal se centró en la excavación de los cimientos de la Fábrica de Tabacos, que dejó a la luz un cementerio paleocristiano de enormes proporciones y abundantes testimonios funerarios con reutilización de materiales romanos, entre los que se encontraban varios epitafios.

Entre los repertorios epigráficos más recientes que mencionan el epitafio de Antonia Clementina, se encuentra Die Römischen Inschriften von Tarraco (RIT 368), obra del investigador alemán Géza Alföldy, publicada en 1975. Además de recoger la tradición historiográfica anterior existente sobre la pieza, el autor señala que el nomen del marido de Antonia, Rufio, vuelve a aparecer en un epitafio localizado en Astorga $^{4}$, ya que en la epigrafía tarraconense únicamente lo encontramos en dos ocasiones 5 . Igualmente menciona la posibilidad de que los jardines en los que se instalara el sepulcro de Antonia Clementina, en las inmediaciones de Tarraco, estuvieran cercanos al bosquecillo donde el emperador Adriano sufriera el ataque de un esclavo demente: apud Tarraconem spatians per virdiaria (Alföldy, 1975, 200).

La labor de investigación arqueológica ha sido, como vemos, y hoy día sigue siendo constante en la ciudad de Tarragona, además de contar con un alto nivel intelectual. Toda esta labor científica también se ha visto acompañada de la conservación de multitud de inscripciones que nos pueden ayudar a reconstruir de manera bastante cercana la sociedad romana de la épo-

3. Los resultados de estos trabajos se publicaron en las Memorias de la Junta Superior de Excavaciones, concretamente en las correspondientes a los años 1928, 1929, 1930 y 1935.

4. CIL II 2659: L(ucio) Rufio Materno / an(norum) XV / L(ucius) Rufius pater / Tryphena mater.

5. El epitafio de Antonia Clementina, que estamos comentando (RIT 368), y RIT 622. 
ca, lo que convierte a la Colonia Tarraco en un lugar privilegiado del Imperio romano.

\section{LA TARRAGONA DE ANTONIA CLEMENTINA}

La Tarragona romana se abrió al mundo con motivo de la elevación de su status jurídico a colonia bajo la denominación de Colonia Iulia Urbs Triumphalis Tarraco, en el siglo I a.C., convirtiéndose en el año 27 a.C. en capital de la provincia Tarraconense, y administrada directamente por el emperador, al igual que la Lusitania. Por las mismas fechas sería nombrada cabeza de conventus, decisión detrás de la cual se encontraba el emperador Augusto, quien permaneciendo una temporada en la ciudad, dirigiría desde allí la reforma administrativa de las provincias del Imperio. Al mismo tiempo se concedió la ciudadanía romana a los habitantes Tarraco, diferenciando, no obstante, a los esclavos (servi), de los hombres libres (ingenui) (Aquilué, Dupré, Massó, Ruiz de Arbulo, 1991, 20-22).

Semejante importancia pasaría a reflejarse de igual manera en la construcción de importantes obras públicas y privadas: sus grandes murallas, que datan del siglo II a.C. (Dupré, 2004, 30), y cuyos restos aún son visibles en el «Paseo de la Muralla», guardaban en su interior los edificios del Foro y la «Torre del Pretorio», datados entre el siglo I a.C., el Foro de la Colonia y I d.C., el Foro Provincial y la «Torre del Pretorio»; y que, de hercúleas dimensiones, pues «los modelos arquitectónicos e iconográficos utilizados en Tarraco procedían directamente de la Urbs» (Aquilué, 2004, 53), permanecerían en activo hasta principios del siglo IV (Dupré, 2004, 43-48); un Anfiteatro, en los restos de cuya arena se instaló hacia finales del siglo VI, tras el abandono del edificio como lugar de espectáculo en el siglo V (Dupré, 2004, 71-72) una basílica visigótica «de tres naves, con santuario, presbiterio de ábside exterior y una pequeña cámara anexa, posiblemente una sacristía» (Aquilué, Dupré, Massó y Ruiz de Arbulo, 1991, 85), para conmemorar el martirio que tuvo lugar el 21 de enero del año 259 del obispo de Tarragona Fructuoso, quien, junto con sus diáconos Augurio y Eulogio, fueron quemados en la arena del Anfiteatro «a consecuencia de la represión contra los partidarios del cristianismo promovida por el emperador Valeriano» (Dupré, 2004, 69). En torno a la misma basílica se generó un pequeño cementerio, permaneciendo con toda probabilidad en uso ambos hasta la ocupación musulmana de Tarraco, acaecida en torno a 713 / 714 (Aquilué, Dupré, Massó y Ruiz de Arbulo, 1991, 85). Junto a la mencionada basílica y los Foros, podemos apreciar los restos del circo, de construcción flavia, y con una longitud estimada en $325 \mathrm{~m}$. «la menor de todos los circos hispánicos, en general extraurbanos», ya que tuvo que adaptarse al espacio que le permitía la alineación de la muralla tardo-republicana. El epitafio del auriga Eutyches ${ }^{6}$, conductor tarraconense de bigae fallecido a los veintidós años debido a una enfermedad, se configura como testimonio que nos pone en relación con los ludi circenses celebrados en el circo (Dupré, 2004, 60-61, 63).

Estos edificios destacan especialmente entre las grandes construcciones de Tarraco, al igual que los localizados en su entorno extraurbano más próximo: tumbas monumentales y mausoleos, acueductos, arcos, como el de Bará y grandes villas, como las de Els Munts, con una ocupación entre los siglos I y VII y Centcelles, entre los siglos II a.C. y IV d.C. (Remolà, 2002, 102, 105-106). Al mismo tiempo se produjo el enriquecimiento y ascenso social de muchas familias en todo el convento tarraconense, como los Iunii y $\mathrm{Li}$ cinii, en Tarraco y Barcelona; los Porcii, en Ampurias y Tortosa, o la misma gens Antonia ${ }^{7}$ en Valentia (Gallego Franco, 1999, 254, nota 5). Los nombres de todos estos individuos, la élite de la ciudad, se trata de los únicos habitantes de Tarraco que conocemos en profundidad, si comparamos sus datos con la mayor parte de la población, mucho más desconocida, entre los que se encontraban trabajadores, artesanos, campesinos y pequeños comerciantes (Aquilué, Dupré, Massó y Ruiz de Arbulo, 1991, 28). Por tanto, la onomástica de esa élite nos habla irremediablemente de su condición jurídica y status socioeconómico (Gallego Franco, 1999, 253-254), que se refleja de igual manera en sus monumentos funerarios; aquí los datos se empiezan a conocer a partir del siglo I a.C., cuando se datan las tumbas monumentales localizadas en la Necrópolis Paleocristiana. Algunas de ellas constituían auténticos recintos para la eternidad provistos de todo tipo de estancias suplementarias dedicadas a asegurar el mantenimiento y cuidado de la tumba y con ello la vida del difunto. El de Antonia Clementina podría ser uno de estos casos.

En cuanto a los enterramientos de época alto-imperial, contamos en este momento con más de doscientas cincuenta inscripciones funerarias que nos ayudan a reconstruir la sociedad de la época. Con una presencia mayoritaria del rito incinerador, que va siendo sustituido por la inhumación, gradualmente en la transición del siglo II al III d.C., predominando finalmente éste último de manera absoluta en los siglos IV y V (TED'A, 1987, 190-191), con la Tarraco cristiana.

La ciudad mantendría su esplendor hasta finales del siglo III d.C., momento en que se produjo un importante

6. CIL II, 4314 $=$ RIT 444. Se conserva en el Museo Diocesano de Tarragona.

7. Los personajes que portaban este nombre en la ciudad de Tarraco estaban relacionados con las clases altas de la ciudad, cfr. M. D. Mirón Pérez $(2000,19)$. 
receso a todos los niveles ocasionado principalmente por la crisis del Imperio y las primeras invasiones germánicas, cuya entrada se señala en 260 d.C., y que originó una gran recesión urbanística. Sus consecuencias serían tremendamente negativas para la urbe, tal como nos relatan escritores de los siglos IV, como Aurelio Víctor (Aquilué, Dupré, Massó y Ruiz de Arbulo, 1991, 30), y V (Macías y Remolà, 2004, 38). Pero fue en la Tarraco del siglo II, en todo su apogeo, donde vivió Antonia Clementina, dama de alto nivel social y económico.

La situación de libertad que, como mujer, disfrutaba entonces Antonia había comenzado a gestarse en el ámbito del imperio poco antes, a mediados del siglo I d.C. Gracias a las reformas llevadas a cabo por Augusto y Claudio algunas mujeres se vieron liberadas de la tutela mulieris (es decir, del control de la figura jurídica del tutor) consiguiendo con ello una autonomía que les permitió, entre otras cosas, la administración personal de su patrimonio, aunque la dote seguía estando en manos del marido.

Una nueva época surgía para la mujer romana, aunque no completamente favorable, que las capacitó para gestionar sus propios asuntos, según apuntaba el jurisconsulto Gayo en el siglo II d.C.: «ipase sibi negotia tractant». Su nueva capacidad jurídica las animó a convertirse en comerciantes y empresarias (Thomas, 2001, 200-203), aunque todavía seguían privadas de aquellas profesiones adscritas a los varones. Pero esto en teoría, ya que también hubo mujeres que accedieron a algunos de estos puestos, como el de abogado. $\mathrm{Me}$ sia Sentinate, Afrania y Hortensia pasaron a la historia por la «osadía» (así se encargarán de reflejarlo los escritores latinos de la época) de atreverse a defender sus intereses mediante la declamación de un discurso en el Foro ante un público masculino. Como no podía ser de otro modo fueron calificadas de mal ejemplo en los Factorum et Dictorum Memorabilium de Valerio Máximo (siglos I a.C.-I d.C.). De Hortensia, para no reconocer el éxito de su discurso, decía que había heredado tal aptitud del famoso orador Quinto Hortensio Hortalo, su padre; como mujer era impensable que se expresara de tal modo (Cantarella, 1996, 132-139).

Si en el mundo itálico la nueva situación se dejó sentir de manera importante, en Hispania, la Colonia Tarraco merece ser destacada por los importantes ejemplos con que contamos. Es la ciudad que nos proporciona un mayor número de datos referidos a la actividad económica de la mujer, y en materia de epigrafía, las dedicatorias femeninas dirigidas a varones superan con creces el número conocido en otras provincias del Imperio (Bravo, 2001, 603).

Este ambiente de mayor participación de las mujeres en la vida social es lo que favoreció la autonomía de féminas romanas tarraconenses, como Antonia Clementina. Su fortuna personal y acomodada posi- ción social de Antonia Clementina la convirtieron en domina de varios esclavos y esclavas, de quienes conocemos el nombre de los que aparecen en su epitafio: Marullo, Antroclo, Helena y Tertullina. Con su manumisión testamentaria para encomendarles el cuidado de su sepulcro ${ }^{8}$, «levantado en un jardín o huerto a las afueras de la ciudad» (Mirón, 2005, 267), en Tarraco algo común, y las disposiciones de su patrona, se convirtieron en sus herederos y cuidadores de su tumba a perpetuidad, pasando esta obligación a sus hijos o a sus manumisos, de modo que el sepulcro no recayera en manos ajenas ${ }^{9} \mathrm{y}$ acabara formando parte de diferentes propiedades territoriales, privándole con ello del acceso a la vía pública que debía tener todo monumento funerario. Publio Rufio Flavo, el marido de Antonia, se encargó de cumplir la última voluntad de su esposa de entregar a aquellos cuatro libertos las tierras que su patrona poseía a las afueras de $\operatorname{Tarraco}^{10}$. Y por supuesto de consignarlo en la piedra (RIT 368):

$\mathrm{D}$ (is) $\mathrm{M}$ (anibus).

Antoniae Clementinae ux(ori) P(ublius) Rufius Fla(v)us

m(aritus) f(ecit) et s(ibi) viv(o); inq(ue) memoriam perpetuam

hortos coherentes sive suburbanum tradidit

5 lib(ertis) libertabusq(ue) ex familia ux(oris) Marullo, Antroclo,

Helenae, Tertullinae; excepitq(ue) ne quis eos venderet, set (sic) per genus ipsorum posses(s)io decurreret vel per atnatos (sic) vel manumissos ${ }^{11}$.

8. «Los esclavos del testador podían ser también herederos si se les concedía al mismo tiempo la libertad», cfr. H. Gallego Franco (2003, 172, nota 3). Por ejemplo, el vínculo de una heredera testamentaria con el difunto o difunta puede ser, como en el caso que nos ocupa, el de liberta, lo que estaría en íntima relación con la manumisión testamentaria. Es el caso de las libertas y libertos testamentarios, cfr. H. Gallego Franco $(2003,199)$.

9. No podía venderse a extraños, «lo que confirma que era factible también que un testador dispusiera lo contrario», cfr. J.F. Rodríguez Neila $(1992,439)$.

10. Con «hortos coherentes siue suburbanum», se explica que las tierras cedidas a los cuatro libertos se situaban «en las inmediaciones de la ciudad», cfr. TED'A $(1987,191)$.

11. «Consagración a los dioses manes. Su marido Publio Rufio Flavo lo hizo (el monumento) para su mujer Antonia Clementina y para él mismo vivo; en cuya memoria perpetua he legado los huertos limitrofes a las posesiones de la ciudad a los libertos y libertas de la familia de mi mujer Marullo, Antroclo, Hellena, Tertullina; estipulando que ellos no los vendieran, sino que las posesiones pasen a través de los descendientes de ellos mismos o a través de los parientes de la familia del padre o sus libertos». 
Este tipo de cláusulas testamentarias eran frecuentes en el mundo romano; de hecho las volvemos a encontrar en un epitafio, también femenino (de modo que, debido a sus características nos es posible establecer un paralelismo con el epígrafe de Antonia Clementina), localizado en Mantua, donde el esposo de la fallecida, el caballero Claudio Amazonio, según el deseo expreso de su esposa, Marcia Aurelia Alexandria, en el testamento de ésta legó a sus libertos y a los descendientes de aquéllos el jardín situado en torno a la tumba de su patrona, para que aquél siempre permaneciese en la familia. Si alguno de ellos lo hubiese transferido o vendido a extraños, prohibición expresa también en nuestro epitafio, hubiera tenido que pagar una multa de 1.200.000 sestercios al erario de los pontífices ${ }^{12}$.

Aunque todo esto también quedó explícitamente plasmado en la inscripción de Antonia Clementina había leyes que, desde el siglo I a. C., preservaban los espacios y monumentos funerarios en virtud de la consideración a perpetuidad que de éstos se tenía como loci religiosi, y a sus tumbas como inalienables ${ }^{13}$. La legislación romana intentó protegerlas, a pesar de que la reutilización de los sepulcros y materiales de estos grandes recintos funerarios es un hecho constatado: de poco sirvieron las multas que, fuera de Hispania, amenazaban a estos osados ciudadanos (Rodríguez Neila, 1992, 440-441). De todo ello se deriva que en este tipo de inscripciones sea continua la insistencia por parte de los difuntos y testadores de que los terrenos legados no se vendan ni pasen a manos extrañas (De Ruggiero, 1962, 1043), utilizando fórmulas como «...neque vendere, neque donationis causa, neque de nomine utrorumque exire possit» (CIL VI 22518), o también «Hos neque dividi neque alienari volo» (CIL V 7454).

El motivo principal de estas disposiciones tan recurrentes era el de evitar que desapareciera el culto a los dioses manes, y como consecuencia el olvido de los mismos: los libertos, convertidos en herederos perpetuos, debían ocuparse del cuidado de las almas de sus patronos, celebrando adecuadamente los ritos en su memoria, pues «El gran deseo que el romano tenía de ser recordado tras la muerte requería emplazar la tumba allí donde pudiera ser fácilmente vista y visitada con ocasión de las preceptivas ceremonias religiosas y para atender su conservación» (Rodríguez Neila, 1992, 438).

12. CIL V 4057 y Staerman y Trofimova $(1979,64)$. En el mundo romano se pueden localizar más casos similares, como por ejemplo: $A E 1940, \mathrm{n}^{\circ}$ 94; $A E 1914, \mathrm{n}^{\circ} 219$; o $A E$ 1925, $\mathrm{n}^{\circ} 87$, entre otros.

13. Aunque la Sententia Senecionis que trataba de controlar la venta de recintos sagrados que contenían tumbas nos indica que tal acción era frecuente; cfr. J.F. Rodríguez Neila (1992, 439).
Para reforzar el derecho de propiedad sobre el recinto sagrado era frecuente la colocación de cipos donde constaban las medidas del mismo. Es posible que en el monumento funerario de Antonia Clementina se colocara algún elemento que delimitara y al mismo tiempo protegiera su espacio; lo que es seguro es que el hortus ${ }^{14}$ mencionado en la inscripción fuera adquirido por la difunta junto a la vía que discurría de camino a la Colonia Tarraco, con la finalidad de instalar en el momento oportuno, junto a esos terrenos, la tumba con sus restos y los de su esposo, además de ayudar a su mantenimiento con la explotación agrícola de las tierras (Rodríguez Neila, 1992, 438-439), de gran importancia en este caso ${ }^{15}$.

Como propietaria de tierras, junto a Antonia Clementina destaca Valeria Faventina, terrateniente (Staerman, 1986, 126) y cuyo nombre recoge una sentencia del 11 de febrero de 193 d.C. (para más exactitud, gobernador de la Tarraconense Novio Rufo, bajo el mandato del emperador Pértinax y donde se desarrolla un litigio limítrofe entre unas propiedades que poseía Valeria en el territorio tarraconense y unos compagani rivi Larensis, colectividad de campesinos regantes (D'Ors, 1953, 361-363; Mentxaka, 2009, 44) que habrían «invadido el límite de sus tierras» (Gallego, 1993, 113). Para Staerman, la sentencia desarrolla un pleito entre una comunidad de campesinos y una terrateniente (Staerman, 1986, 126), con bastante probabilidad desarrollado en el ámbito geográfico de Cataluña, concretamente en Aeso (Isona, Lérida), al igual que opinan Alföldy, Pons y Fabre ${ }^{16}$; «en el extremo Noroeste de Cataluña (Pallars o Ribagorza), posiblemente en los alrededores de la población de Pont de Suert» (Pons, 1979, 116); además, el nomen Valerius es bastante común en la zona, y especialmente cuando se acompaña del cognomen Faventi$n u s$, cuyos ejemplos se localizan todos en Cataluña ${ }^{17}$ : dos en Barcino (actual Barcelona), Quintius Valerius Faventinus y Valeria Luci filia Faventina, identificada ésta última por Mariner posiblemente con la Valeria Faventina de la sentencia del año 193; y uno en Aeso

14. Su propiedad también podía ser llamada horti u hortulus, cfr. J.M.C. Toynbee $(1971,97)$.

15. La importancia del cultivo de este hortus estriba en su cercanía con respecto a la Colonia Tarraco, ya que los recursos obtenidos podrían venderse fácilmente y con éxito en la ciudad, aunque también dependiendo del tipo de cultivo que se desarrollase en los mismos. Cfr. A. Prieto $(1986,128)$.

16. Alföldy (1975, RIT 143, p. 78), Pons (1982,115), y Fabre $(1990,326)$.

17. Pons, J. (1982, 113). La inscripción de Quintius Valerius Faventinus, se puede localizar en S. Mariner, IRB 217; la de Valeria Luci filia Faventina, en CIL II 4591 y S. Mariner, IRB 212,; y la de Lucius Valerius Luci filius Galeria Faventinus, el duonviro de Aeso, en CIL II 4468. 
(actual Isona, en Lérida), el duonviro Lucius Valerius Luci filius Galeria Faventinus, y que Alföldy relaciona mediante lazos de parentesco (Alföldy, 1975, RIT 143; Pons, 1979, 113-114). Precisamente es el individuo de Aeso quien Fabre supone antepasado de Valeria Faventina (Fabre, 1990, 323).

La sentencia finalmente resultaría favorable a Valeria Faventina, a quien se le restituyeron sus «derechos vulnerados» (Pons, 1979, 121) y «demuestra que la capacidad de la mujer hispanorromana para poseer tierras y sus derechos como propietaria no se ven en modo alguno mermados por su condición femenina, y parece claro, a pesar de no conocer los detalles de este pleito, que el poder social y la influencia de esta rica latifundista se impuso sobre las modestas comunidades campesinas» (Gallego, 1993, 113).

El hecho de ser propietaria de uno o varios terrenos extraurbanos era un aspecto positivo más de la nueva situación, y de gran importancia, pues la posesión de tierras constituía la base del poder económico de las mujeres latifundistas, y la principal fuente de su riqueza (Gallego, 1993, 113). En este sentido la evolución favoreció con el tiempo a las mujeres como es apreciable en el caso de Melania Iunior (siglo V), nieta de Melania la Vieja, de origen hispano; fue propietaria de varios terrenos distribuidos por todas las provincias occidentales, con más de ocho mil esclavos que los trabajaban, siendo éstos finalmente manumitidos y sus terrenos donados a la Iglesia (Bravo, 2001, 608-609).

A los derechos de propiedad se unía la capacidad de testar, tal como hemos visto en Antonia Clementina. Originada en el período republicano, se reafirmó en el Alto Imperio con el apoyo de la nueva situación jurídica de las mujeres. Concretamente en la provincia Tarraconense, el testamento femenino cuenta con unas características singulares: las últimas voluntades de las difuntas suelen demandar a los herederos la colocación de un monumento funerario, tanto para ellas, como para las personas que aquellas elijan (Gallego, 2006, 153). Aún destacaremos que estos epígrafes son de carácter privado, en razón de la privilegiada situación económica y social de las difuntas. Por tanto, la colocación de los monumentos en lugares públicos constituye una muestra más de la influencia de estas élites sobre el resto de los ciudadanos (Gallego, 2006, 155-156). Este es el caso de Fulvia Celera (RIT 322) (Fig. 2), «flamínica perpetua de la Colonia Tarraconense» $\mathrm{y}$ «flamínica de la provincia Hispania Citerior», que dejó como disposición testamentaria la colocación de dos estatuas: una para ella y otra para su marido, el flamen Cayo Vibio Latro (procedente de Sigarra, RIT 312). Del cumplimiento se encargaron dos de sus libertos, Fulvio Museo (quien llegaría a ser seviro augustal (RIT 906) y Fulvio Moscho. Aún nos es conocido otro liberto, Fulvio Diadocho, quien dedica en vida una ins-

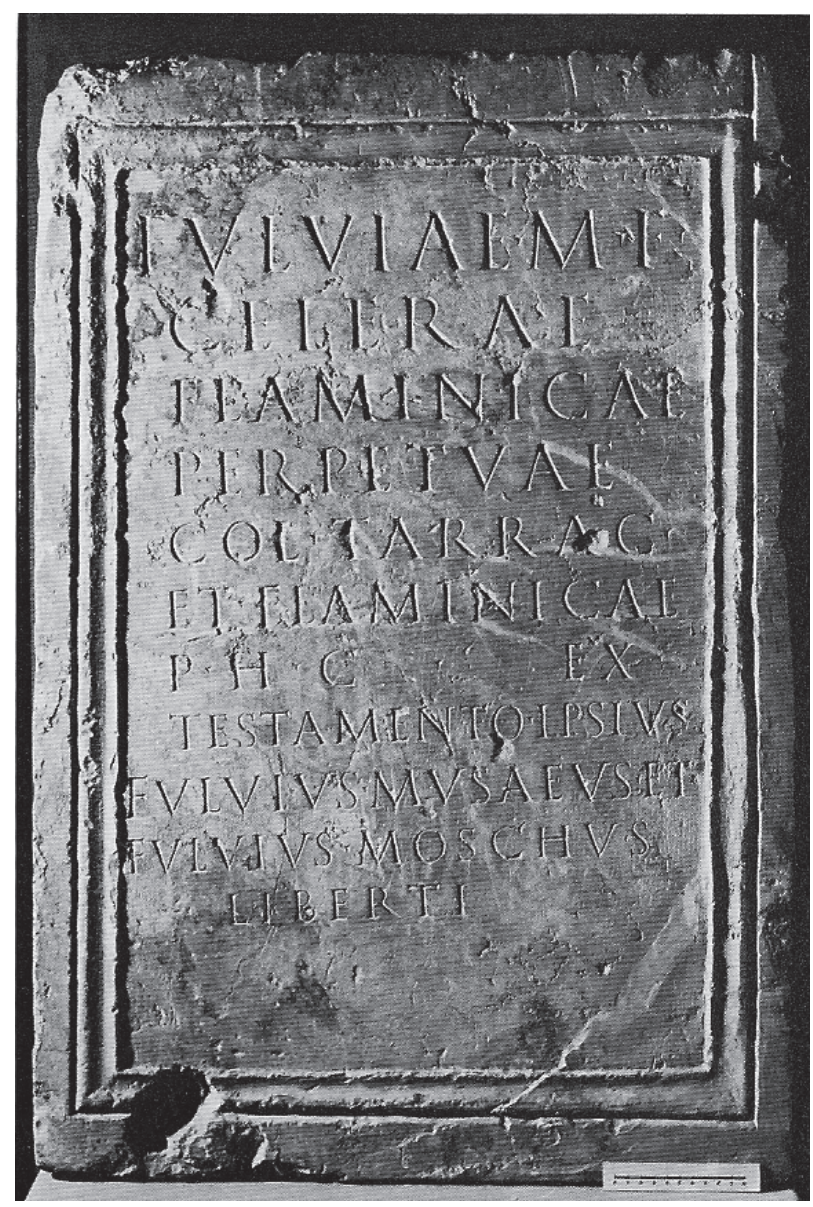

Figura 2: Pedestal de estatua de Fulvia Celera realizada por dos de sus libertos: Fulvio Museo y Fulvio Moscho. Alföldy, G., 1975: Die römischen Inschriften von Tarraco, Berlín, lámina XXXVI 4.

cripción honorífica (RIT 344) a su patrona, donde la reconoce «flamínica perpetua de la Concordia Augusta». Dama de gran poder político, económico y social en un extenso radio, tanto en la Colonia Tarraco como en la provincia Hispania Citerior, parece ser que, al igual que Antonia Clementina, fue poseedora de patrimonio y de un número importante de esclavos, además de los que conocemos por la epigrafía.

En cuanto a la forma que supuestamente tenía el recinto de Antonia, que bien pudiera ser de dimensiones notables en razón de las medidas de la inscripción: 87 x $126 \mathrm{~cm}$, sabemos que los acotados funerarios podían contar con multitud de elementos, teniendo en cuenta no obstante el tamaño de aquellos. Un acercamiento a tales accesorios lo podemos encontrar en la descripción que hace de su tumba uno de los personajes literarios del Satyricón de Petronio, el liberto Trimalción; éste manda construirse un complejo funerario fastuoso complementado con árboles frutales y viñas, entre otros elementos, además de una gran estatua con su efigie, y un reloj ornado de relieves: «Horologium in 
medio, ut quisquis horas inspiciet, velit nolit, nomen meum legat» ${ }^{18}$.

Algunos de estos grandes acotados podían contar en su interior con aedificia donde se ubicaban cenacula y tabernae para la celebración de las ceremonias que honraban a los fallecidos, otro tipo de pabellones como diaetae, solaria, terrazas para tomar el sol, horrea, cisternae para abastecer de agua, piscinae, canales, etc. Todo decorado con árboles frutales, plantas y flores como las violetas y rosas (Toynbee, 1971, 97), «símbolo de eterna primavera» (Vaquerizo, 2001, 296). Muchos epitafios hacen referencia a ello, como uno de los recogidos por Ausonio ${ }^{19}$ :

«Sparge mero cineres bene olentis et unguine nardi, hospes, et adde rosis balsama puniceis.

Perpetuum mihi ver agit inlacrimabilis urna et commutavi saecula, non obii»

Además, las almas de los difuntos encontraban en la decoración vegetal de estos horti un agradable reposo $^{20}$ :

«...los huertos de frutales en torno a las tumbas sirven para que, después de la muerte, las almas encuentren reposo en un lugar agradable»

Estos recintos también podían disponer de capillas e incluso estructuras domésticas para los libertos encargados de su mantenimiento (Mirón Pérez, 2000, 20). Para ayudar a preservar todos estos elementos, y lo más importante, las tumbas, estos espacios podían estar cercados mediante pequeños muros o balaustradas, los murus o maceria (Toynbee, 1971, 97). Todo ello los configuraba como residencias preparadas para el más allá. Las disposiciones que legaban una propiedad en la que se hallaba una tumba a libertos encomendándoles el cuidado a perpetuidad de la misma eran muy frecuentes, constituyendo práctica habitual, según observa el orador Quintiliano (siglo I d.C.) entre otros autores latinos ${ }^{21}$ :

18. «Pondrás en el centro del monumento un reloj de sol, con tal artificio dispuesto, que cuando miren la hora tengan a la fuerza que leer mi nombre», cfr. Petronio, Satyricon, 71.

19. «Riega mis cenizas de vino y de perfumado aceite de nardo, oh huésped, y añade bálsamo a las rosas rojas. Mi urna no llorada goza de una perpetua primavera. No he muerto; sólo he cambiado mi mundo», cfr. Ausonio, Epitaphia, XXXI.

20. Deutero-Servius o Servius Danielinus, Comentario a la Eneida, VI, 764, cfr. D. Vaquerizo (coord.), Funus cordubensium. Costumbres funerarias en la Córdoba romana, Córdoba, 2001, 286.

21. «Si un hombre ordena enterrar su cuerpo in culto loco y lega, según la costumbre, para proteger sus cenizas, una gran extensión de terreno a tomar por sus herederos alrededor del monumento...», cfr. Quintiliano, Institutio Oratoria, 7.9.5. «...ut si quis corpus suum in culto loco poni iubeat, circaque monumentum multum agri ad heredibus in tutelam cinerum...»

Y Petronio, que pone en boca de Trimalción las siguientes palabras: «uno de mis libertos se encargará de custodiar mi tumba, para que no se ensucien en ella los transeúntes», habiendo manumitido en su testamento a todos sus libertos (Petronio, Satyricon, 71).

Esta disposición legal se originó en el siglo II a.C. en Italia: un grupo de libertos recibía una propiedad en arriendo debiendo ocuparse de su explotación; «según Escévola, a la herencia de estos libertos tenían derechos los hijos de éstos pero no podían enajenar los lotes que les hubieran correspondido e incluso debían abonar a los herederos del testador una cierta suma anual» (Prieto, 1986, 127).

Staerman ha estudiado en profundidad esta cuestión, concluyendo que por encima del cuidado de la tumba se encontraba la obtención de una ganancia (Staerman, 1986, 118): «Del mismo modo que en Italia, pues, también en Hispania los libertos permanecían en íntima unión con la familia en el clan de su patrono. Esto era mucho más posible, si los libertos mantenían con los patronos una unión económica, esto es, si arrendaban o poseían parcelas que eran sustraídas de las fincas de los patronos si daban a éstos una parte de la cosecha o ejecutaban algún tipo de trabajo en las villae en que se formaban los colegios de culto familiares. Una unión tal muestra que los libertos, cuando todavía eran esclavos, trabajaban en la agricultura y que los dueños, a consecuencia del temprano comienzo de la crisis en Hispania, convirtieron a esclavos y libertos en colonos» (Staerman, 1986, 118-119). Por tanto, la crisis del régimen esclavista que afectó a Hispania hacia mitad del siglo II, y cuyo origen se puede buscar en la clase de los esclavos rurales (Staerman y Trofimova, 1979, 66), fue la responsable de la evolución, o transición, de este sistema esclavista hacia uno nuevo, el del colonato (Staerman, 1986, 127).

Pero, como dicen Staerman y Trofimova, «es lícito pensar que la transmisión de fincas a grupos de libertos podía tener también lugar cuando el propietario estaba aún vivo» (Staerman y Trofimova, 1979, 64). En este sentido, y referente al epitafio de Antonia Clementina, Elías Riera señaló que se trataba «de una donación hecha en vida del propietario y que surte todos sus efectos antes de la muerte del mismo» (Elías Riera, 1946, 5). Esta afirmación parece estar realizada en base a que uno de los cónyuges, el marido de la fallecida, y quien se encarga de dedicar el epitafio, hace la donación en vida de las tierras que poseía su mujer a los cuatro libertos de ésta, para que cuidaran a perpetuidad del sepulcro que sería para ambos, en virtud del testamento de aquélla. Pero la propietaria de las tierras, tal como 
señala la inscripción, y los diversos trabajos de investigación sobre la misma, era la difunta Antonia Clementina, por tanto la donación se realizaría con ocasión de la muerte de la propietaria.

De la lectura de los testamentos se deduce que la propiedad legada a los libertos lo era «con su equipamiento, con los esclavos y, naturalmente, con todos los bienes anejos a la finca», que los libertos podían dejar en herencia a sus hijos, pero no enajenar. Se creaba entonces lo que Staerman y Trofimova llamaron con acierto «una comuna campesina», donde «los copropietarios debían al amo y a sus herederos una cierta contribución, probablemente subdividida en razón proporcional a la parte de tierra de cada uno de los libertos, pero de la que el colectivo respondía solidariamente» (Staerman y Trofimova, 1979, 64).

Éste, pues, había sido el motivo principal, evolucionando hacia el mantenimiento tanto físico como religioso del sepulcro, cuando esta disposición entró en materia funeraria (Prieto, 1986, 127). Puede que estas obligaciones exigidas a los libertos y libertas tuvieran relación con el vínculo que les seguía ligando con su patrón o patrona tras la manumisión ${ }^{22}$, ya que la prohibición de la venta de los terrenos que les eran legados reforzaría ese vínculo concreto, deduciendo por tanto que el mantenimiento del sepulcro se trataba de una simple excusa para legitimar tal acción (TED'A, 1987, 191). Se puede decir que libertos y libertas estaban en la «obligación» de cumplir con tales preceptos en agradecimiento a su nueva condición jurídica, «perpetuando los lazos de dependencia aún después de la muerte» (Mirón, 2005, 267).

\section{CONCLUSIÓN}

Hemos podido apreciar que las cláusulas desarrolladas en la inscripción de Antonia Clementina estaban basadas en un modelo testamentario regulado y asegurado por la ley y muy común en el Imperio Romano: el de la manumisión testamentaria, que tuvo una amplia trascendencia y desarrollo. Todo ello iba dirigido a preservar tanto el culto ritual necesario a los dioses manes como el cuidado del sepulcro y las propiedades en las que aquél estaba levantado y que eran necesarias para el mantenimiento del recinto funerario. Precisamente semejante insistencia legal se derivaba de las intromisiones que en estos espacios se practicaron ya en época romana, quedando como consecuencia algunas tumbas abandonadas en territorio de nadie. Aunque la muerte definitiva de los difuntos realmente llegaba con su olvido, de ahí el que las tumbas se dispusieran a am-

22. M.D. Mirón Pérez (2000, 19-21). Los libertos debían manifestar de este modo el agradecimiento a sus patronos por haberles concedido la libertad. bos lados de las vías, e incluso algunas exhortaran al caminante a pararse unos instantes para poder leer su historia.

En esta misma época, a mediados del siglo I d.C., surgía también una nueva situación jurídica para la mujer romana; algunas de ellas, gracias a la relajación en incluso eliminación de la tutela mulieris comenzaron a disfrutar de una mayor autonomía. La inmediata consecuencia fue el aumento de comerciantes y empresarias, mujeres que podían disponer de su patrimonio. Pero a esta nueva incorporación femenina en la sociedad influyó igualmente la necesidad de que muchas de ellas desempeñaran ciertos oficios y se ocuparan de tareas de administración de los negocios y patrimonios familiares, debido a que un buen número de varones se encontraba luchando en los distintos frentes abiertos del Imperio, o bien, en el caso de las élites, desempeñando el cursus honorum ecuestre y senatorial, en buen número de provincias.

El epitafio de Antonia Clementina refleja a la mujer romana de alto nivel socio-económico que ya disfrutaba plenamente de la nueva situación jurídica femenina; gracias a ello, tuvo la oportunidad de poseer y administrar su patrimonio de manera personal, tanto en tierras como en esclavos y esclavas. Por último, la capacidad de redactar testamento permitió darle a sus terrenos un último sentido eterno, instalando en ellos el sepulcro que guardaría sus restos y los de su esposo, bajo el cuidado perpetuo de sus libertos y los descendientes de éstos, de modo que siempre fuera recordada en la Colonia Iulia Urbs Triumphalis Tarraco.

$\mathrm{M}^{\mathrm{a}}$ Carmen Delia Gregorio Navarro
C/ Paula Montal Fornés, no $8,5^{\circ} \mathrm{B}$
50018 Zaragoza
boudicasafo@hotmail.com

\section{BIBLIOGRAFÍA}

CIL: Corpus Inscriptionum Latinarum.

ILS: Inscriptiones Latinae Selectae.

RIT: AlföLDY, G., 1975: Die römischen Inschriften von Tarraco, Berlín.

AlFÖLDY, G., 1984, «Drei städtische Eliten in römischen Hispanien», Gerión, 2, 193-238.

Aquilué, X., Dupré, X., Massó, J. y Ruiz de Arbulo, J., 1991: Tarraco. Guía Arqueológica, Tarragona.

Aquilué, X., 2004: «Arquitectura oficial», en X. Dupré RAVENTós (ed.), Las capitales provinciales de Hispania, vol. 3, Tarragona. Colonia Iulia Urbs Triumphalis Tarraco, 41-53, Roma.

Batlle Huguet, P., 1979: La Catedral de Tarragona, León.

Beneyto Pérez, J., 1931: Fuentes del Derecho Histórico Español, Barcelona.

Boy, I., 1713: Recopilación sussinta de las antiguedades romanas $q$ se allan del tiempo de los Emperadores romanos en la ciudad de Tarragona y su cercanias. Copia- 
das y escritas de las mesmas antigüedades por Ioseph Boy Ingeniero en dicha ciudad. Año 1713, Tarragona.

Bravo, G., 2001: «La mujer en la economía de la Hispania romana», en G. Duby y M. Perrot (dir.), Historia de las mujeres, tomo I: La antigüedad, 602-609, Madrid.

Cantarella, E., 1996: Pasado próximo. Mujeres romanas de Tácita a Sulpicia, Valencia.

De Morales, A., 1575: Las antigüedades de las ciudades de España, Alcalá de Henares.

De Ruggiero, E., 1962: Dizionario Epigraphico de Antichità romane, vol. III, Parte II, L'erma di Bretschneider-Roma.

D’Ors, A., 1953: Epigrafía jurídica de la España romana, Madrid.

Dupré Raventós, X. (ed.), 2004: Las capitales provinciales de Hispania, vol. 3, Tarragona. Colonia Iulia Urbs Triumphalis Tarraco, Roma.

Dupré RAVentós, X., 2004: «Edificios de espectáculo» en X. Dupré RAVENTÓs (ed.), Las capitales provinciales de Hispania, vol. 3, Tarragona. Colonia Iulia Urbs Triumphalis Tarraco, 55-72, Roma.

ElíAs RiERA, A., 1946: «La lápida de Antonia Clementina en la Catedral de Tarragona, y su relación con la historia del Derecho Romano», Boletín Arqueológico de Tarragona, fasc. 1-2 enero junio, 3-9.

FABRE, G., 1990: «Une aproche des stratégies familiales: le comportement des notables dans la Tarraconaise nordorientale vu à travers l'exemple d'Aeso-Isona (fin I-II siècle ap. J.-C.)», en J. Andreau y H. Bruhns (eds.), Parenté et strategies familiales dans l'Antiquité Romaine (París, 1986), Col. EFR, 129, 311-331, París-Roma.

Figuerola Mestre, J., Gavaldà Bordes, J., Menchon Bes, J., Teixell Navarro, I., Muñoz Delgar, A. y Macías Solé, J.M., 2001-2002: «La Catedral de Tarragona. Obres de restauració i treball arqueològic», Lambard, 14, vol. 2001-2002, 75-108.

Gallego Franco, H., 1993: «La mujer hispanorromana y la actividad socioeconómica: las profesiones», Minerva: Revista de Filología Clásica, 7, 111-128.

Gallego Franco, H., 1999: «Imagen onomástica y social de la mujer hispanorromana en las fuentes epigráficas de Lleida y su provincia», Revista d'Arqueologia de Ponent, 9, 253-261.

Gallego Franco, H., 2003: «Herederas hispanorromanas: su caracterización onomástica y social a través de las fuentes epigráficas», Hispania Antiqua, 27, 171-200.

Gallego Franco, H., 2006: «El uso del testamento entre las mujeres hispanorromanas. El testimonio de las fuentes epigráficas», Hispania Antiqua, 30, 143-166.

Macías Solé, J.M. y Remolà Vallverdú, J. A., 2004: «Topografía y evolución urbana», en X. Dupré RAventós (ed.), 2004, Las capitales provinciales de Hispania, vol. 3, Tarragona. Colonia Iulia Urbs Triumphalis Tarraco, 27-39, Roma.

Macías Solé, J. M., Menchon Bes, J. J., Muñoz Melgar, A. y Teixell NaVArro, I., 2006: «Intervencions arqueològiques a la catedral de Tarragona: treballs del Pla director
(2000-2002)», Tribuna d'arqueologia, vol. 2003-2004, 221-246, Barcelona.

Mentxaka, R., 2009: «Lex Rivi Hiberiensis, derecho de asociación y gobernador provincial», Revista Internacional de Derecho Romano, 2, abril 2009, 1-46. Revista en formato electrónico: http://www.ridrom.uclm.es/documentos2/Asociacion_pub.pdf

Mirón Pérez, M.D., 2000: «Antonia Clementina», en C. Martínez, R. Pastor, M. J. De La Pascua y S. Tavera (dirs.), Mujeres en la Historia de España. Enciclopedia Biográfica, 19-21, Madrid.

Mirón PÉReZ, M.D., 2005: «Religión y poder», en I. Morant (dir.), Historia de las mujeres en España y América latina. De la Prehistoria a la Edad Media, tomo I, 2005, 243-275, Madrid.

Morera y LlaURAdó, E., 1894: Tarragona antigua y moderna, Tarragona.

Pons, J., 1979: «Propiedad privada de la tierra y comunidades campesinas pirenaicas. Análisis de una sentencia judicial del año 193», Memorias de historia antigua, 3, 111-124.

Prieto, A., 1986: «Algunos datos sobre las formas de propiedad de la tierra en la Cataluña romana según las fuentes epigráficas», Estudios de la Antigüedad, 3, 125-131, Barcelona.

Ramos, M.L., 1995: «Santa María de Tarragona», en Catalunya Romànica. El Tarragonés, El Baix Camp, L'Alt Camp, El Priorat, La Conca de Barberà, volumen XXI, 122- 170, Barcelona.

Remolà Vallverdú, J.A., 2002: «Centcelles y las villae de Tarraco durante la Antigüedad tardía», en J. ARCE (ed.): Centcelles, el monumento tardorromano, iconografia y arquitectura, Bibliotheca Italica, Monografías de la Escuela Española de Historia y Arqueología en Roma, 25, 97-112, Roma.

Rodríguez NeILA, J.F., 1992: «Algunas observaciones sobre los acotados funerarios romanos», In memoriam $\mathrm{J}$. Cabrera Moreno, Granada, 437-448.

Ruiz de Arbulo, J., y MAR, R., 1997: «Arqueología y planificación urbana en Tarragona. Tradición historiográfica y realidad actual», Recuperar la memoria urbana. La arqueología en la rehabilitación de las ciudades históricas, Tarragona.

Staerman, E.M., y Trofimova, M.K., 1979: La esclavitud en la Italia imperial, Madrid.

Staerman, E.M., 1986: «Las provincias hispanas», en A. García Bellido et alii (dirs.), Conflictos y estructuras sociales en la Hispania Antigua, 115-128, Madrid.

Thomas, Y., 2001: «La división de los sexos en el Derecho romano», en G. Duby y M. Perrot (dirs.), Historia de las mujeres, tomo I: La antigüedad, 136-203, Madrid.

ToynBeE, J.M.C., 1971: Death and burial in the Roman World. Aspects of Greek and Roman Life, London.

Vaquerizo, D. (coord.), 2001: Funus cordubensium. Costumbres funerarias en la Córdoba romana, Córdoba. 